Article

\title{
Modelling Variation in Petroleum Products' Refining Footprints
}

\author{
Eric Johnson $1, *(1)$ and Carl Vadenbo ${ }^{2}$ (I) \\ 1 Atlantic Consulting, 8136 Gattikon, Switzerland \\ 2 Ecoinvent Association, 8005 Zurich, Switzerland; vadenbo@ecoinvent.org \\ * Correspondence: ejohnson@ecosite.co.uk; Tel.: +41-447-721-079
}

Received: 26 September 2020; Accepted: 5 November 2020; Published: 10 November 2020

\begin{abstract}
Energy-related greenhouse gas emissions dominate the carbon footprints of most product systems, where petroleum is one of the main types of energy sources. This is consumed as a variety of refined products, most notably diesel, petrol (gasoline) and jet fuel (kerosene). Refined product carbon footprints are of great importance to regulators, policymakers and environmental decision-makers. For instance, they are at the heart of current legislation, such as the European Union's Renewable Energy Directive or the United States' Renewable Fuels Standard. This study identified 14 datasets that report footprints for the same system, namely, petroleum refinery operations in Europe. For the main refined products, i.e., diesel, petrol and jet fuel, footprints vary by at least a factor of three. For minor products, the variation is even greater. Five different organs of the European Commission have estimated the refining footprints, where for the main products, these are relatively harmonic; for minor products, much less so. The observed variation in carbon footprints is due mainly to differing approaches to refinery modelling, especially regarding the rationale and methods applied to assign shares of the total burden from the petroleum refinery operation to the individual products. Given the economic/social importance of refined products, a better harmony regarding their footprints would be valuable to their users.
\end{abstract}

Keywords: petroleum refinery operation; carbon footprints; refined petroleum product; life cycle assessment (LCA); co-product allocation

\section{Introduction and Objective}

Petroleum products fuel much of modern life. Of all energy types, crude petroleum oil has the largest market share, accounting for 33\% of the global and 36\% of the European energy use. Second is natural gas, at $24 \%$ both globally and in Europe [1]. In turn, greenhouse gas (GHG) emissions from energy systems drive the carbon footprints of most production systems. With some exceptions, e.g., in agriculture or halon applications, energy production and consumption account for the majority, if not the vast majority, of life-cycle emissions.

Therefore, the carbon footprints of crude oil are important. Furthermore, footprints of its production show large variations, mainly because of regional differences in crude oil quality, extraction technologies and efficiencies. According to Masnadi et al. [2], production carbon intensities (CIs) have national averages that range from around 3-20 $\mathrm{g} \mathrm{CO}_{2} \mathrm{e} / \mathrm{MJ}$, spread around a global average of 10.3, whilst some individual oil fields have CIs as high as 50. Jing et al. [3] report national average production CIs ranging from $3.3 \mathrm{~g} \mathrm{CO}_{2} \mathrm{e} / \mathrm{MJ}$ in Denmark to $29.2 \mathrm{~g}$ in the Democratic Republic of Congo.

This variation in production of crude oil has been recognised by regulators in the recent revisions of the European Union's Fuel Quality Directive [4-6]. As part of those analyses, the Marketable Crude Oil Name (MCON) system was used as the basis for oil sector pathway definitions and 115 pathways of oil products were considered. The 2018 revision of the Fuel Quality Directive did not apply all 
115 pathways, but for petrol and diesel, it differentiated footprints for five generalised pathways: conventional crude, natural gas-to-liquid, coal-to-liquid, natural bitumen and oil shale [7]. The U.S. State of California's Air Resources Board (CARB) has also built this production CI variation into its Low Carbon Fuel Standard (LCFS) [8]. Under the LCFS, footprints of gasoline (i.e., petrol) and diesel are considered as providing an additional burden for crude oil production (currently $12.26 \mathrm{~g} \mathrm{CO}_{2} \mathrm{e} / \mathrm{MJ}$ ), based on a 3-year-average of California petroleum supplies.

However, what about petroleum refining? Unlike production, refining's CI variety has not yet been incorporated into regulations. However, it is noticeable and to some extent recognised; furthermore, as this study shows, it can be significant. In contrast to the variation in petroleum production footprints, which are caused by physical/operation variety, this paper shows that the variation in petroleum refining footprints is primarily due to differences in inventory modelling. Models of the same system, namely, European refineries, come up with a variety of footprints for the same products. The objective of this study was chiefly to document the variety in reported carbon footprints for the refining step of refined petroleum products. To avoid complications that are possibly presented by variations in physical/operational differences, the analysis was restricted to the combined refining system of a single geographical area, namely, that of Europe (EU + Norway).

What is the novelty of this paper in relation to the existing body of literature on this topic? Moretti et al. explored the variation of a single refining model with respect to allocation methods [9]. For the evaluation of the results, the authors introduced a "hydrogen-based consistency test" and compared the results to those derived from an industry model [10] that uses a marginal approach. Abella \& Bergerson examined the differences caused by variations in the crude quality and refinery configuration in Canada [11], and Jing et al. did a similar comparison globally, providing carbon intensities for national refinery operations based on the country-specific crude supply and refinery industry data [3]. Sphera, IFP \& EUCAR compared the attributional and consequential approaches and results of two refinery models [12]. Additionally, a subgroup of the European Petroleum Refiners Association, called CONCAWE, has for some years addressed the issue of footprint variations in its Refinery Technology Support Group, of which many members are refinery modellers. Some of its findings are presented in $[10,13,14]$; this research is well-known among European refinery modellers.

To the best of the authors' knowledge, no study has so far attempted to gather and discuss the variation of refinery carbon footprints from different sources for a specific region, and for a wider set of refined petroleum products. As such, this paper is the first to compile and compare all known carbon footprints for total refinery operations in Europe, where we found 12 unique datasets showing considerable variation between them and hence warranting a deeper analysis. This fills an important knowledge gap that is of high relevance for public policies and regulations, while providing a basis for further investigation.

Similar analyses surely could be done for other regions; indeed, one study was done of transport fuels in the USA [15]. However, its scope was from well-to-wheel and included biofuels, and its focus was more on the methods of biofuel footprinting.

\section{Materials and Method}

The method of the study involved desk research to identify published datasets of carbon footprints or carbon intensities of European refining (i.e., as industry averages); these datasets served as the main materials of the study. In some cases, an analysis was done to extract the refining footprint from a larger well-to-tank footprint, followed by evaluation, analysis and discussion of the results.

\subsection{What the Datasets Represent}

All these datasets, with three exceptions, were generated using mathematical models that are generalised representations of European refining. They were modelled in either of two general ways: (1) the model represents one or more "typical" European refinery set-ups in terms of the configuration and complexity, or (2) the model represents an aggregation of all European refineries, i.e., as if all 
refineries were combined at one physical site. Either way, a specific crude slate (i.e., the input of crude petroleum oil) was defined, which was then processed by the different units (atmospheric distillation, vacuum distillation, hydrocracking, fluid catalytic cracking and so on), thereby consuming energy, releasing emissions and generating intermediates and final products. The emissions that arose directly from the individual refinery steps or from the energy supply or other auxiliary processes were partitioned and/or allocated to those products and summed to provide a per-product footprint.

The exceptions in this study are three "black box" models ([9] also refers to black box models as "aggregate refinery-level" models), wherein neither the refinery configuration nor the complexity are clearly defined. Instead, total-refinery emissions are estimated and then allocated across the products. In one of those two cases [16], the refinery configuration seems to have an influence on allocation factors.

\subsection{The Functional Unit}

The functional unit of the datasets is the lower heating values of 14 refined products: liquefied petroleum gas (LPG), petrol, naphtha, kerosene/jet fuel, diesel, heating oil, marine gasoil, heavy fuel oil, bitumen, petroleum coke, lubes/wax, sulphur, hydrogen, and fuel gas. The authors have normalised the measure of that unit to megajoules. As is discussed below (Section 4.4), with the possible exception of diesel and light heating oil, it appears that the datasets use similar or identical definitions of the refined products.

\subsection{Partitioning and Allocation of a Multi-Product System}

Apportioning environmental burdens among products in a multi-product system is a classic methodological issue in a life-cycle assessment (LCA) and carbon footprinting that has been addressed many times in the literature, for example, in [17]. For that matter, apportioning cost burdens is a classic (and similar) issue in management accounting within production companies (such as refineries).

As shown in the Results section below, the datasets discovered in this study applied three partitioning approaches, constituting different degrees/perspectives of representation of refinery complexity, which are as follows: black box (no partitioning); marginal partitioning, i.e., the incremental emissions required to produce an additional unit of a given product, which is usually calculated using a linear-program (LP) model; unit process, the partitioning of the refinery into its constituent processes, with emissions allocated to unit-process outputs in proportion to their mass, energy content or economic value.

\section{Results}

Fourteen sources of refined product footprints were identified (Table 1). Two of these, from Eurobitume and the Joint Research Centre (JRC), are available in multiple allocation keys. Three of the studies, namely, from Ecofys, DG Environment and the Petroleum Refinery Life Cycle Inventory Model (PRELIM) consortium, present aggregated data for the well-to-tank phase, but without breaking down the refining step. There is some overlap of sources: JRC publishes its own footprints, with input from CONCAWE, and supplied the footprints to DG Energy; Sphera/Thinkstep has also published footprints and supplied them to DG Environment; the Institut für Energie und Umweltforschung (IFEU) has contributed to the footprints used by the ecoinvent association and DG Climate. 
Table 1. European refined product footprints, by source.

\begin{tabular}{|c|c|c|c|}
\hline Source & Partitioning & Allocation Key & References \\
\hline CONCAWE & Marginal (LP) & Mass & [13] \\
\hline Ecofys & Marginal & Energy & [18] \\
\hline ecoinvent LCI database & Unit process & Energy & [19] \\
\hline ESU & Black box (no partitioning) & Energy & [16] \\
\hline Eurobitume & Unit process & $\begin{array}{c}\text { i. Economic } \\
\text { ii. Subdivision of processes (As } \\
\text { defined in ISO standards and } \\
\text { elsewhere, whereby a multi-product } \\
\text { process is subdivided into multiple } \\
\text { processes) }\end{array}$ & $\begin{array}{l}{[20]} \\
{[21]}\end{array}$ \\
\hline European Commission, DG Climate & Unit process & Energy & {$[22]$} \\
\hline European Commission, DG Energy & Marginal (LP) & Unclear & [23] \\
\hline European Commission, DG Environment & Unit process & Appears to be energy & [24] \\
\hline $\begin{array}{l}\text { European Commission, Joint Research } \\
\text { Centre }\end{array}$ & $\begin{array}{l}\text { i. Marginal (LP) } \\
\text { ii. Black box } \\
\text { iii. Black box }\end{array}$ & $\begin{array}{l}\text { i. Energy } \\
\text { ii. Economic } \\
\text { iii. Added value }\end{array}$ & [9] \\
\hline IFP & Marginal (LP) & Economic & [25-28] \\
\hline Plastics Europe & Black box (no partitioning) & Mass & [29] \\
\hline PRELIM consortium & Unit process & Energy & [3] \\
\hline Sphera/Thinkstep & Unit process & Energy & [12] \\
\hline Statoil & Unit process & Energy & [30] \\
\hline
\end{tabular}

DG: Directorate General, ISO: the International Standards Organisation, LCI: Life Cycle Inventory, LP: Linear

Program, PRELIM: Petroleum Refinery Life Cycle Inventory Model.

From these resources, 17 footprint datasets were discovered (Table 2). Five of these, three from JRC and two from Eurobitume, were the same dataset calculated with different allocation keys. Therefore, arguably, there were only 12 unique datasets. Four of them, from DG Climate, Ecofys, DG Environment and PRELIM, do not break down the contribution stemming from refining from the well-to-tank footprints. Two of those do, however, give some detail. DG Climate reported that its refining footprints are "in line with CONCAWE model used in JEC for conventional crude chains" [22]. The PRELIM consortium [3] reported a footprint range for all refined products of 1.7-12.3 $\mathrm{g} \mathrm{CO}_{2} \mathrm{e} / \mathrm{MJ}$.

Most sources covered only a limited set of the final products that can be obtained from petroleum refineries, and instead focused on the main ones (diesel, petrol and jet fuel). Eurobitume and Plastics Europe covered only the refined products of direct interest to their organisations, respectively, bitumen and naphtha.

The datasets were characterised both by partitioning and by allocation key (Table 1). It was observed that in many textual descriptions of the datasets, the distinction between partitioning and allocation was non-existent or unclear. For that matter, the relevant ISO standard [31] conflates the two, saying that partitioning falls under the approaches available to address the allocation problem in multi-output product systems. For this study, however, a distinction was made between these concepts: partitioning is understood here as the way a life-cycle system is broken into parts, i.e., constituting alternative representations of system complexity and causality. In this context, a petroleum refinery can be subdivided into its interconnected parts, such as individual unit process parts or a marginal part (with the aim to capture the consequences of the production of an incremental barrel of some product). Alternatively, it can be not partitioned, as in the case of a black box, leading to the entire operation (or at least all product-refining steps) to be considered as one single activity. Allocation, by contrast, is the key by which the environmentally relevant flows, such as the resources consumed and the emissions released, are distributed amongst each part's co-products. 
Table 2. Carbon footprints of refined petroleum products by the sources and allocation key (in grams of $\mathrm{CO}_{2}$ e per MJ lower heating value).

\begin{tabular}{|c|c|c|c|c|c|c|c|c|c|c|c|c|c|c|c|}
\hline Source & $\begin{array}{l}\text { Allocation } \\
\text { Key }\end{array}$ & $\begin{array}{l}\text { Liquefied } \\
\text { Petroleum } \\
\text { Gas (LPG) }\end{array}$ & Petrol & Naphtha & $\begin{array}{l}\text { Kerosene/ } \\
\text { Jet Fuel }\end{array}$ & Diesel & $\begin{array}{l}\text { Heating } \\
\text { Oil }\end{array}$ & $\begin{array}{l}\text { Marine } \\
\text { Gasoil }\end{array}$ & $\begin{array}{c}\text { Heavy } \\
\text { Fuel } \\
\text { Oil }\end{array}$ & Bitumen & $\begin{array}{l}\text { Pet } \\
\text { Coke }\end{array}$ & $\begin{array}{l}\text { Lubes/ } \\
\text { Wax }\end{array}$ & Sulphur & Hydrogen & $\begin{array}{c}\text { Fuel } \\
\text { Gas }\end{array}$ \\
\hline CONCAWE & Mass & 5.2 & 5.5 & 6.7 & 6.1 & 7.2 & 4.7 & 2.9 & -3.7 & -10.1 & -25 & 14.1 & -1.3 & & \\
\hline ecoinvent & Energy & 6.9 & 7.7 & 2.2 & 4.7 & 4.7 & 4.7 & & 2.4 & 4.4 & 5.1 & 19.2 & 14.6 & 7.4 & 6.8 \\
\hline Ecofys & Energy & \multicolumn{14}{|c|}{ Results for refining only are not broken down. } \\
\hline ESU & Energy & 8.4 & 8.5 & 4.3 & 5.7 & 5.8 & 5.8 & & 4.6 & 4.9 & 6.0 & & & & 5.7 \\
\hline Eurobitume & Economic & & & & & & & & & 0.93 & & & & & \\
\hline Eurobitume & Subdivision & & & & & & & & & 0.47 & & & & & \\
\hline $\begin{array}{l}\text { European Commission, } \\
\text { DG Climate }\end{array}$ & Energy & \multirow{2}{*}{\multicolumn{14}{|c|}{$\begin{array}{l}\text { Study says its "findings [are] in line with CONCAWE." } \\
8.6\end{array}$}} \\
\hline $\begin{array}{l}\text { European Commission, } \\
\text { DG Energy }\end{array}$ & & & & & & & & & & & & & & & \\
\hline $\begin{array}{l}\text { European Commission, } \\
\text { DG Environment }\end{array}$ & Energy & \multicolumn{14}{|c|}{ Results for refining only are not broken down. } \\
\hline $\begin{array}{l}\text { European Commission, } \\
\text { Joint Research Centre }\end{array}$ & Energy & & 5.8 & & 6.1 & 7.2 & & & -4.3 & & -24.8 & & & 122.9 & \\
\hline $\begin{array}{l}\text { European Commission, } \\
\text { Joint Research Centre }\end{array}$ & Economic & & 5.9 & & 7.8 & 8.4 & & & -17.4 & & -58.7 & & & 92 & \\
\hline $\begin{array}{l}\text { European Commission, } \\
\text { Joint Research Centre }\end{array}$ & Added value & & 6 & & 7.9 & 10.3 & & & -29.8 & & -80.4 & & & 57.7 & \\
\hline $\begin{array}{l}\text { 'IFP (The footprint } \\
\text { values come from [26]) }\end{array}$ & Economic & & 2.7 & & & 0.8 & 0.3 & & 0.4 & & & & & & \\
\hline Plastics Europe & Mass & & & 2.5 & & & & & & & & & & & \\
\hline PRELIM consortium & Energy & \multicolumn{14}{|c|}{ The volume-weighted average refining carbon intensity $(\mathrm{CI})$ of all 343 crudes vary within $10.1-72.1 \mathrm{kgCO}_{2} \mathrm{e} / \mathrm{bbl}$ or $1.7-12.3 \mathrm{gCO}_{2} \mathrm{e} / \mathrm{MJ}$. } \\
\hline Sphera/Thinkstep & Energy & & 9.6 & & 2.5 & 3.4 & & & 4.1 & & & & & & \\
\hline Statoil & Energy & & 6 & & & 3.3 & & & & & & & & & \\
\hline
\end{tabular}




\section{Discussion}

The refining carbon footprints reported for European refined petroleum products had a remarkable variation. Those reported by five different organs of the European Commission also varied, but not as much as the entire range of datasets. With the studies either departing from the same input data, or in several cases, even building on each other (at least in part), the footprint variation was mainly due to differences in modelling approaches. Some of the variation was also likely due to differences in data collection and perhaps to reference years. The boundary between two products, diesel and heating oil, was also unclear.

\subsection{Variation of Refinery Carbon Footprint Values}

A simple inspection of the footprints in Table 2 reveals the vertical variation between them, i.e., footprints for the same product vary by dataset. The footprint of diesel, for example, was reported as being as low as 0.8 and as high as $10.3 \mathrm{~g} \mathrm{CO}_{2} \mathrm{e} / \mathrm{MJ}$ of the lower heating value.

To characterise this variation, a large-small spread was calculated as the largest absolute footprint divided by the smallest absolute value (Table 3). In the case of negative values, the spread factor was the absolute difference of the largest and smallest (most negative) divided by the largest (most positive). For example, for diesel, the spread was 10.3/0.8 $=12.9$. The largest value was nearly 13 times that of the smaller one. A formal measure of variation, such as the standard deviation, was not applied because the footprint sample per refined product was small (10 at most, for only diesel and petrol).

Table 3. Large-small spread of the reported footprints for each refined product.

\begin{tabular}{cc}
\hline Refined Product & Footprint Spread Factor \\
\hline Heating oil & 19.4 \\
Hydrogen & 16.6 \\
Pet coke & 14.4 \\
Diesel & 12.9 \\
Heavy Fuel oil & 7.4 \\
Petrol & 3.6 \\
Kerosene/jet & 3.2 \\
Bitumen & 3.1 \\
Naphtha & 3.0 \\
LPG & 1.6 \\
Lubes/wax & 1.4 \\
Fuel gas & 1.2 \\
Sulphur & 1.1 \\
Marine gas oil & $\mathrm{NA}$ \\
\hline
\end{tabular}

The large-small spread of footprints for each refined product was significant (Table 3). The major refined products were diesel, petrol and jet fuel (Figure 1), which accounted for two-thirds of European refinery output [32] and all have at least a factor of three between their largest and smallest values. Variation also characterised the non-primary products' footprints (Figure 2). 
12.0

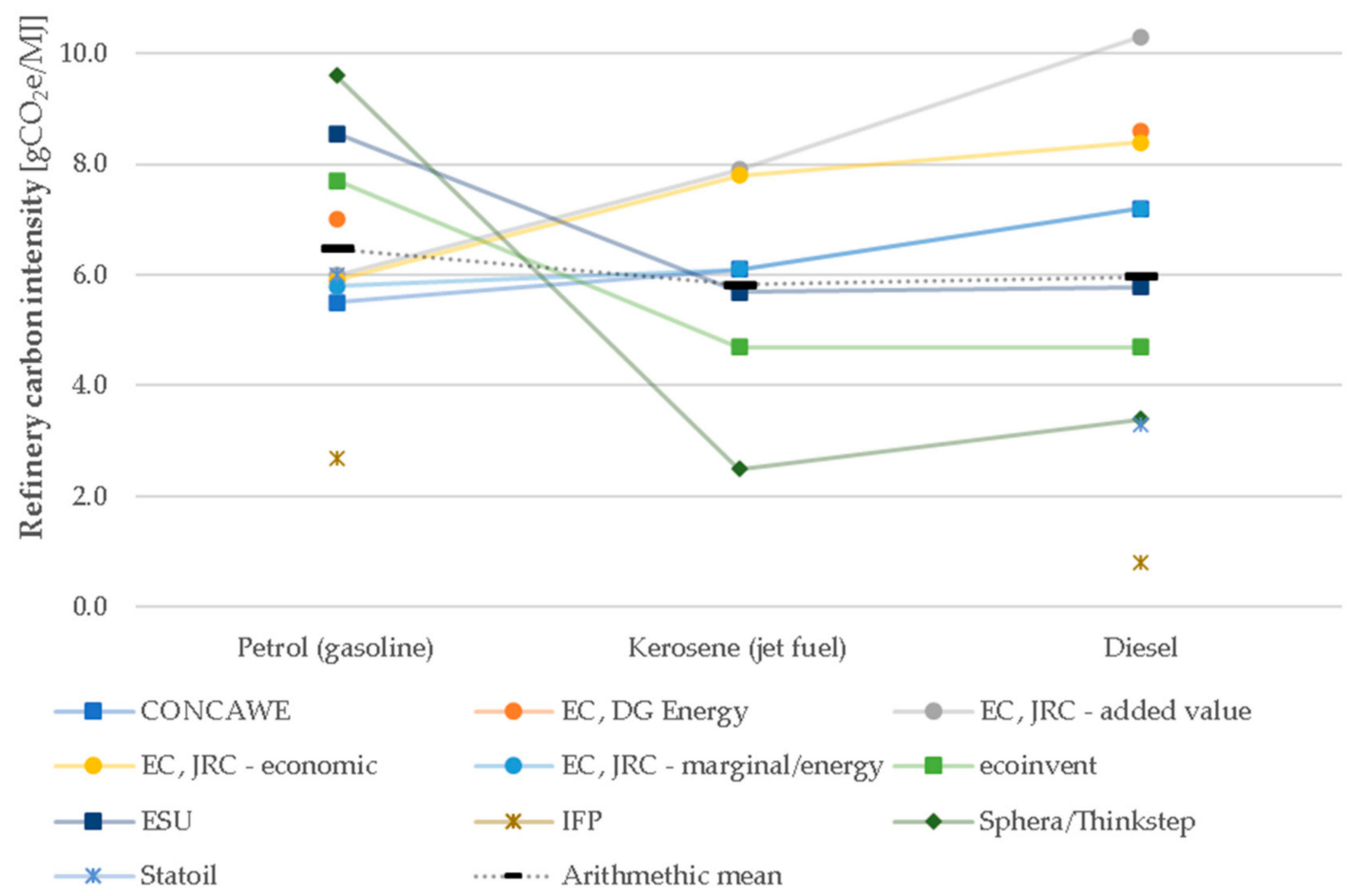

Figure 1. Variation of the reported footprints, for primary products. EC: European Commission, JRC: Joint Research Centre.

150.0

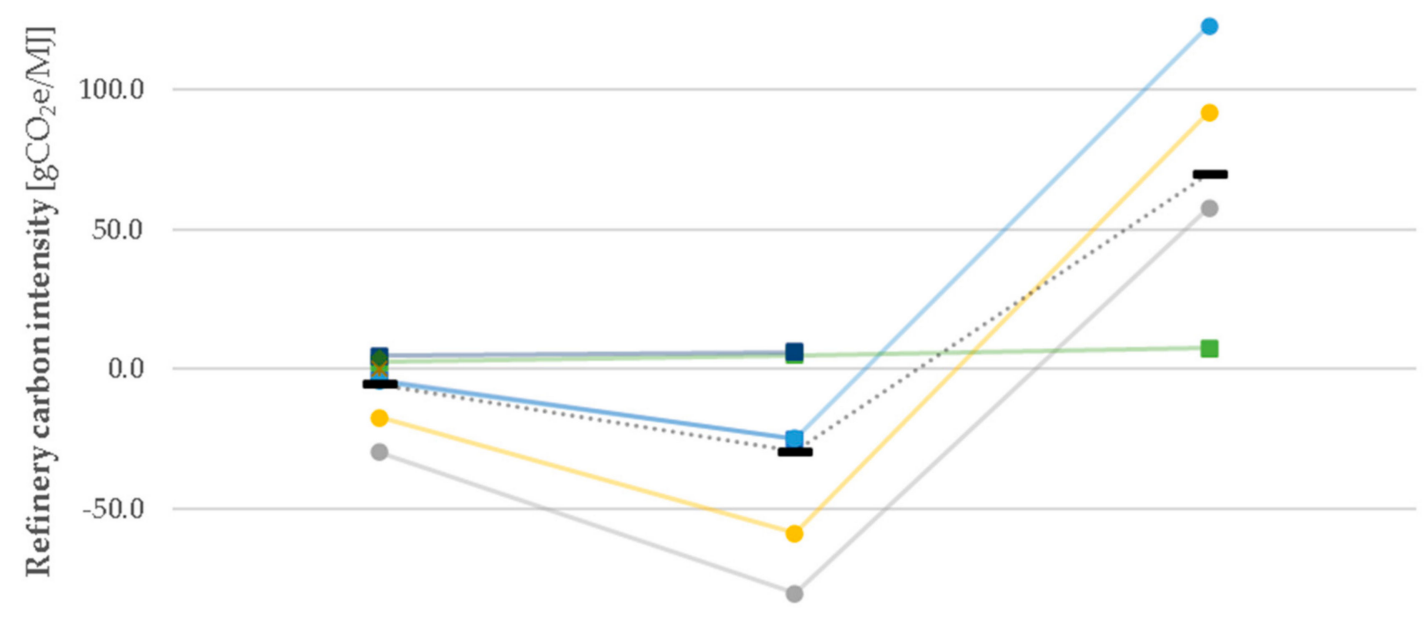

$-100.0$

Heavy fuel oil Pet coke

Hydrogen

\begin{tabular}{|c|c|c|}
\hline$\because$ CONCAWE & —EC, DG Energy & $\longrightarrow$ EC, JRC - added value \\
\hline$\longrightarrow \mathrm{EC}, \mathrm{JRC}$ - economic & $\longrightarrow \mathrm{EC}, \mathrm{JRC}$ - marginal/energy & - ecoinvent \\
\hline$\because-\mathrm{ESU}$ & *-IFP & $\multimap$ Sphera/Thinkstep \\
\hline * Statoil & ...- $\cdots$ Arithmethic mean & \\
\hline
\end{tabular}

Figure 2. Variation of the reported carbon footprints for the three most-spread, non-primary products.

Another way to characterise this variation would be to define it as a share of the cradle-to-grave footprint of a given refined product. The weighted average footprint of global crude oil production is 
$10 \mathrm{~g} \mathrm{CO}_{2} \mathrm{e} / \mathrm{MJ}$ [2]; the combustion footprint of diesel, petrol and jet fuel is about $73 \mathrm{~g} \mathrm{CO}_{2} \mathrm{e} / \mathrm{MJ}$ [33]. Therefore, this variation for diesel could be calculated as $(10.3-0.8) /(10+73+10.3)=10.2 \%$.

The horizontal variation, i.e., the spread of carbon footprint values within a given source, was not consistent (Figures 1 and 2); there was no consistent higher-lower pattern to the sources.

Negative footprints were reported by some of the sources for four products: heavy fuel oil (HFO), bitumen, petroleum coke (pet coke) and sulphur. This was a consequence of heavier products needing less refining, resulting in lower energy demand and reduced refinery emissions overall, and the marginal method accounting for the emissions avoided by not converting these products further (e.g., to the main transport fuels) [9]. This implies that while the overall burden of refinery operations remained the same, the lighter and more refined fractions were assigned the full additional (i.e., marginal) burden from process steps that are intended to increase the yield of these products, e.g., hydrocracking.

\subsection{Was the Variation Unusual and Does It Matter?}

The footprints of fuels can vary significantly. A clear example is the list of footprints reported for biofuels in Annex V of the revised Renewable Energy Directive [34]. For example, the default footprints for ethanol from only one feedstock, i.e., sugar beets, vary from 47 to $76 \%$ of the fossil fuel comparator. However, this variation is purportedly due to differences in the physical systems for processing sugar beets, not to the different methods used when modelling those systems.

The fact that the Renewable Energy Directive documents such variation (for some 54 pages) suggests its importance and highlights the complexity. Fuel footprints, relative to other fuels or to the same fuels from other sources or production routes, are central to greenhouse gas regulations and therefore to commercial practice in the fuels' supply chain.

\subsection{Multiple Views of the European Commission}

Four organs of the European Commission have sponsored the estimation of refined product refining footprints: DGs Climate, Energy and Environment, and the Commission's Joint Research Centre. CONCAWE, a division of the European Petroleum Refiners Association, can also be considered to fall within the realm of the Commission in this context because its footprint model is the reference for EU legislation [9]. Two of these sources, namely the DG Climate and DG Environment, did not publish disaggregated results, with the refining-only portions shown separately, for their carbon footprints, but as noted above, DG Climate reported that its refining footprints were in line with CONCAWE model.

With respect to the major products of diesel, petrol and jet fuel, the Commission's footprints had factors of 1.3-1.4. For the peripheral products of heavy fuel oil, petroleum coke and hydrogen, the spread factors were much larger: 8.1,3.2 and 2.1, respectively.

\subsection{Refinery Modelling as the Main Source of Variation}

The main source of carbon footprint variation appeared to be the approach taken towards refinery modelling. All datasets are purported to represent the same system: European (EU + (the European Free Trade Association) EFTA) refineries, albeit the datasets from ecoinvent and ESU explicitly excluded Switzerland (which has a single, small refinery). Instead, there are different ways of assigning the overall burden arising from the petroleum refinery operation to the individual product outputs. The differences in partitioning and allocation, where both are normative modelling aspects, are widely recognised as contributing to the variation. There was some variation among the datasets as data sources and methods of data collection, which appeared to have had some impact on the overall variation. The varied age of the datasets did not seem to significantly affect the overall variation.

\subsubsection{Partitioning}

The partitioning methods accounted for some of the overall variation between the footprints. Within the main products, marginal partitioning generally gave diesel (and distillates) a higher 
footprint than unit process average-based partitioning, while the inverse was true for petrol (Figure 3) (the black-box method seemed attuned to the attributional method; rather than breaking the refinery into multiple unit processes (boxes), it treated the entire refinery as a single box, but the basic approach was the same, so strictly speaking not marginal). This makes sense, given that European refineries were already configured to maximise their diesel output because Europe imports diesel to meet its demand and exports petrol [32].

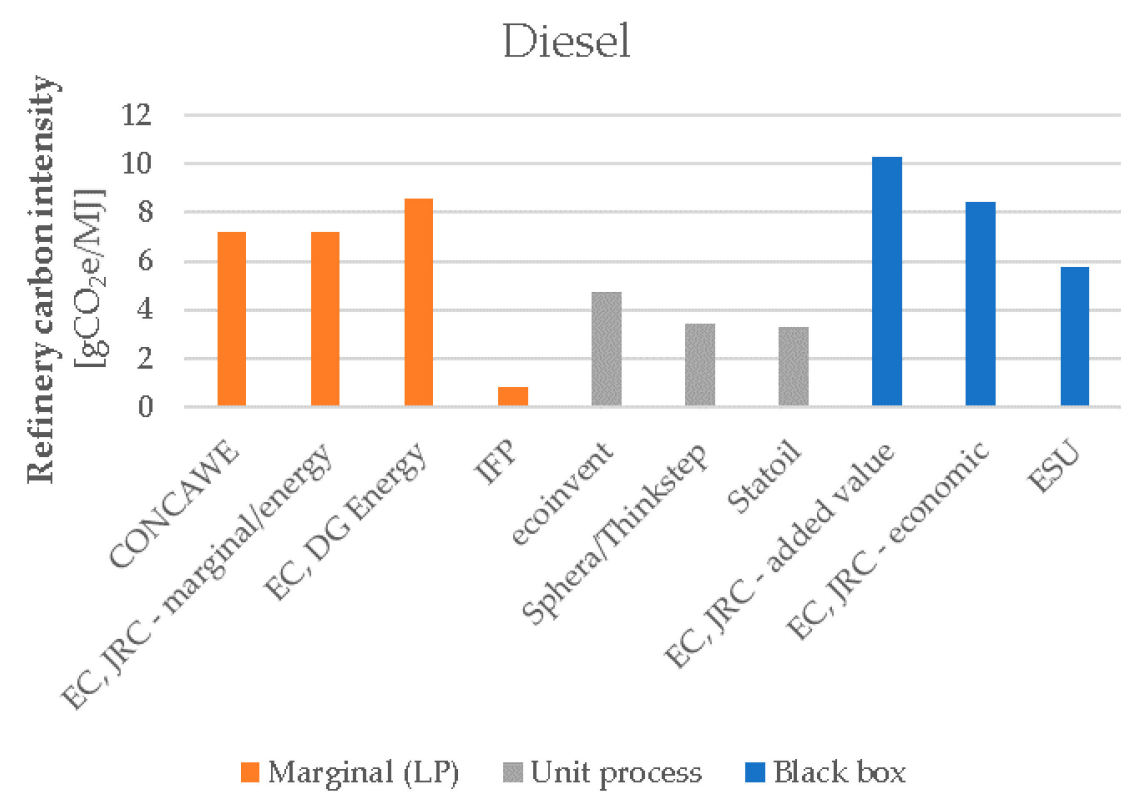

(a)

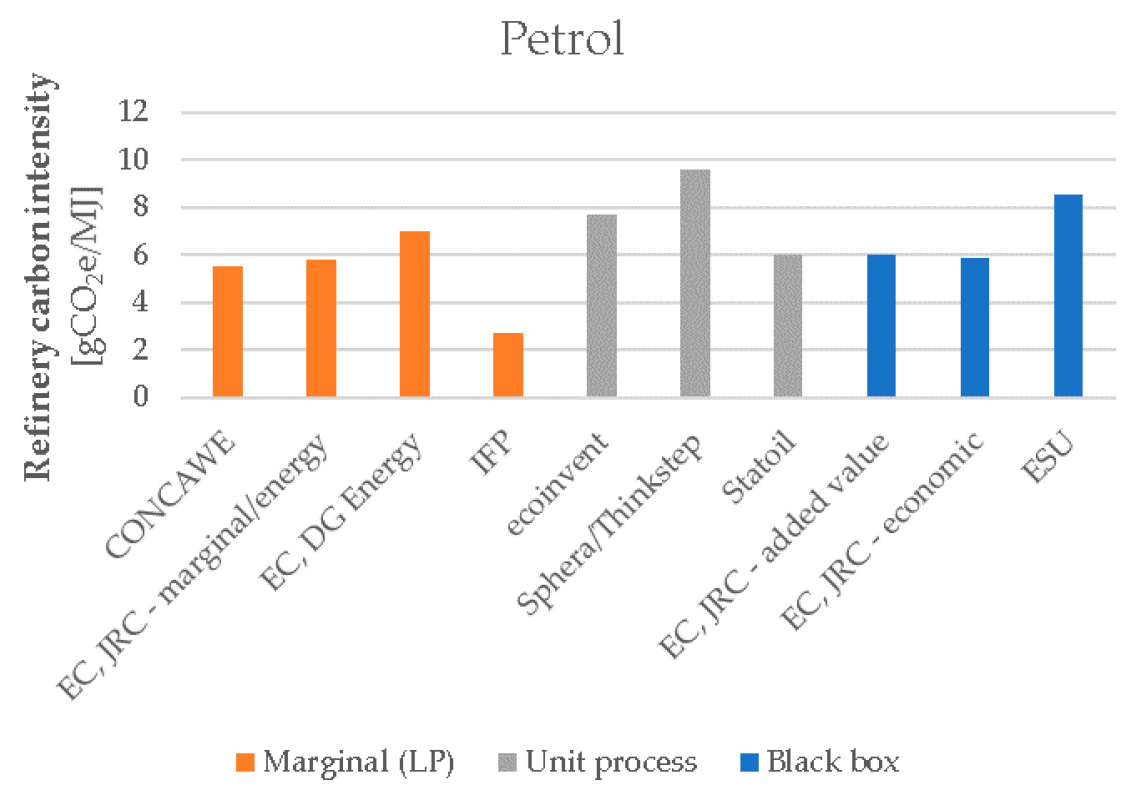

(b)

Figure 3. Cont. 


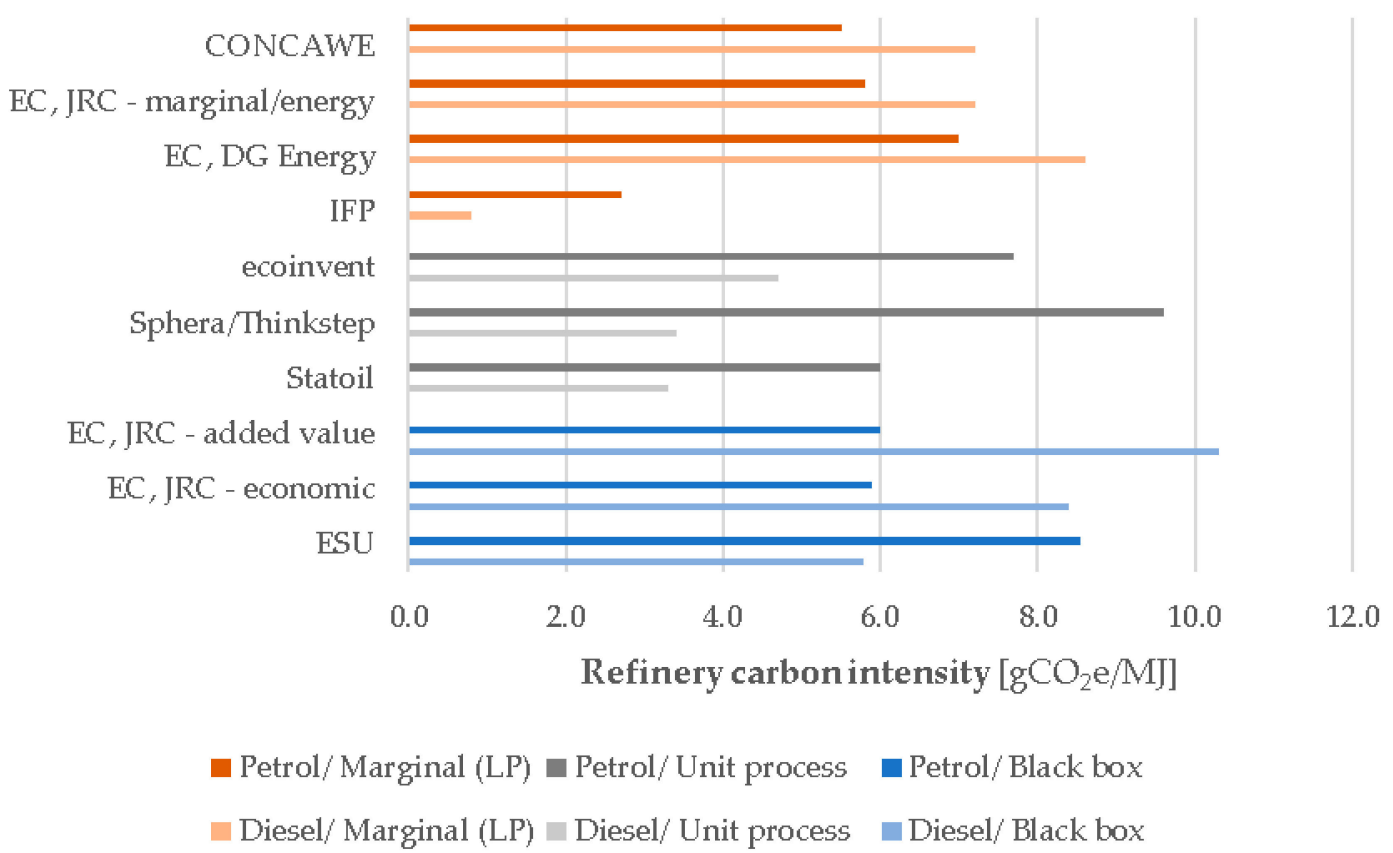

(c)

Figure 3. Comparison of diesel/petrol footprints by partitioning method: (a) diesel, (b) petrol and (c) petrol and diesel.

Sphera, IFP \& EUCAR contended that the diesel-petrol difference is due to differences in how the methods treat hydrogen from the refinery's catalytic reformer [12]. The marginal partitioning methods put more of the burden on hydrogen, while unit-process methods put more of the burden on the reformate (which goes mainly to petrol). Indeed, NETL \& U.S. Dept. of Energy [35] proposed a separate partitioning of hydrogen within the refinery, but this approach did not seem to have been adopted by any of the European dataset producers.

For peripheral products, the variation of the unit process versus the marginal partitioning was more significant. Spreads were much larger (Figure 1) and marginal partitioning generated negative footprints for some products. As Moretti et al. pointed out in [9], negative footprints reflect the fact that refineries would reduce emissions if they sold more of these products by avoiding the emissions associated with the conversion into lighter products under a given set of demand and capacity constraints. Seen in an economic light, this is reasonable because these are unavoidable co-products, some of which can be called residues [36] (one heavy grade of fuel oil is even called "resid"). Upgrading them into main products causes additional emissions and reduces yields at the refinery. At the same time, the resulting negative footprints can be problematic, in that they:

- Can confuse non-experts: It might be seen that if more, say, heavy fuel oil (HFO) or petroleum coke were used, the environment will be burdened less. "Use more HFO, save the planet". This is not the case from a life-cycle perspective: while supplying more HFO or coke as final products (rather than upgrading them to other fuels) reduces the overall emissions at the refinery, it also passes emissions down the supply chain to the user. That is, any perceived "benefits" in refining can be expected to be eliminated when the full life cycles (i.e., cradle to grave) up until the combustion of the heavy products are considered. The trade-offs here are worth further investigation.

- Add greatly to footprint variance. Of course, the same could be said for the other attributional method; however, the point is that the variance is wide.

Differences in partitioning have been addressed by several authors. IFP has made the case for the marginal method in numerous papers [25-28,37,38]. IFP also was a driving force in CONCAWE's adoption of this method [13] (this is acknowledged in the paper and confirmed 
in personal communication with A. Tehrani Nejad), which according to Moretti et al. [9] is now the reference in EU legislation. By contrast, a recent study sponsored by the European Commission [22] declined to use the CONCAWE model because of its "incremental" partitioning method based on marginal analysis; a disaggregated unit process model with step-by-step co-product allocation was used instead.

The black box method without partitioning was adopted by a relatively old study [29] that reported only one product footprint, namely, for naphtha. Two more recent studies $[9,16]$ adopted a similar approach, in which the total resource use and emissions from refinery operations were assigned to the individual products predominantly in a "top-down" fashion ((Moretti et al. presents not only a black box; it also presents two models that use black box partitioning and one that uses marginal (LP) partitioning [9]). In this case, though, the authors applied various factors to reflect the differences in the routes and degrees of refining needed to obtain the final products. Its footprints were higher than many of the datasets, but this was probably due not to partitioning but to the sources of data (see Section 4.4.3.). The black box or top-down approach differs from the unit-process-partitioned models in that it aggregates all conversion steps together from the refinery input to the refinery output, whereas the datasets in this study were based on unit processes and were generated by modelling each major process in the refinery separately. The latter approach enables the resource use and emissions of a particular unit process to be distributed over its specific (intermediate and/or final) co-products, with the carbon footprints of the final products subsequently derived by summing up the results of the relevant process steps/routes. The attributional approaches for assigning the burdens of a specific process step or the entire refinery to the respective product outputs are, nonetheless, similar.

Two artefacts associated with partitioning merit further research. One is the relationship between unit-process fuel types and product footprints. For instance, fluid-cat-crackers are fired mainly by the coke that accumulates on its catalyst. This coke is burned to regenerate the catalyst and to fuel the process. Being similar to coal, this coke is very carbon-intense; therefore, cat cracker outputs bear a higher footprint than those same products coming from other refinery units when accounting for this difference. It would be interesting to see a comparison of footprints that are calculated using unit-specific fuels versus a common fuel mix across the entire refinery.

The other artefact is the definition of residues (or unintended products) in unit-process partitioning. Fehrenbach et al. [36] defines: residues as streams that are bottoms in two consecutive unit-processes; distillates are always considered as products. However, (1) the same study does not classify bitumen as a residue; (2) liquefied petroleum gas (LPG), which is always a distillate, might be considered a residue (albeit not a bottom), in that most refiners try to minimise its production due to its relatively low market value.

\subsubsection{Allocation}

Among the main refined petroleum products, allocation based on mass or energy content yield almost identical results because their energy densities are very similar. For peripheral products, this is not the case, and several products are not used for energy: namely bitumen, lubes/wax, sulphur and some petroleum coke. Only one source shows this difference $[20,21]$. The spread of an economic allocation basis to an allocation based on physical causality (heating energy requirements (that is, the allocation is based on the relative amount of heat (energy) required to make each product)) for bitumen is a factor of 2. This was less than the overall spread for bitumen (Table 3).

ESU-Services [16] used energy as its allocation key, but not the "per-MJ-of-product" approach applied in other energy-allocated datasets. Instead, it applied "energy factors" that were derived from a study published in 1996 (from a paper cited as: Jess A. (1996) Der Energieverbrauch zur Herstellung von Mineralölprodukten, In: Erdöl-Erdgas-Kohle, 112(5), pp. 201-205), where they are reported as a percentage of the refinery average energy required to process a given product. 


\subsubsection{Sources of Data and Methods of Collection}

Petroleum refineries are complex, with a network of interconnected unit processes. Data gathering for life-cycle inventories is a serious challenge in the quantification and assessment of the environmental impacts. As shown by the studies covered for this analysis, there are two main approaches in the literature for constructing life-cycle inventories and deriving carbon footprints for refinery operations:

- Engineering models of a refinery (i.e., as a collection of interconnected unit processes), which are used in all but three of the datasets.

- Top-down estimation of resource use and emissions from the literature and industry statistics, as applied by one case in [9] and also by [16,29].

Of the 11 product carbon footprints reported by ESU-Services [16], five were the highest of all datasets (Table 2) (the refinery carbon footprints were derived by subtracting the impact of the crude oil supply in Europe [39], p. 23, as "crude oil, import mix, at long distance transport $/ \mathrm{kg} / \mathrm{RER}$ " from the GHG indicator results presented in [16], p. 51). The reasons for this are not obvious, but it was likely due to this different approach used for sourcing and collecting data. This was unlikely to be a significant variable in those that use a similar approach, especially in five of the six datasets from the European Commission and the CONCAWE dataset, which were presumably based on a common set of raw data. The one European Commission dataset not in common, namely, that from DG Climate, reported that its findings were in line with CONCAWE's findings (Table 2).

\subsubsection{Age of the Datasets}

The age of the datasets did not appear to be a significant variable. The two significantly older datasets, namely, Plastics Europe and Statoil, reported footprints that fell in the range of the more modern datasets. This was the case even though CONCAWE [13] noted that since the early 2000s, there have been significant changes in European refineries, including their crude slates, product demands, configurations and capacities.

\subsection{Product Category Boundaries}

Two sets of paired products seemed to have ambiguous boundaries. Diesel and heating oil are paired products in that they are chemically similar (and sometimes even identical). Petrol and naphtha are paired in that they have similar properties: whereas petrol is more aromatic, petrochemical naphtha is more aliphatic, but both have similar boiling ranges. For the four sources that report footprints for both pairs (Table 2), the values for petrol and naphtha footprints always differed from each other, suggesting that they were indeed modelled as different products, either obtained over different process routes or not assigned identical allocation factors.

However, for diesel and heating oil, two sources reported the same footprint for them, while the other two reported different values. This suggests a possible difference of opinion, by source, as to the definitions of diesel and heating oil. It also suggests that other sources, which report only diesel and not heating oil, may have assumed the two to be the same output. At the same time, it is also possible that similar (or identical) products were coming from different unit processes and therefore considered as separate products, although in the real-world market, they are not separate.

\section{Conclusions}

This study found that the reported footprints for the European refining of the main refined products, namely, diesel, petrol, and jet fuel, varied by a factor of three. For minor and peripheral products, the variation was even greater, reaching a maximum of almost 20. There was also horizontal variation within each dataset; this did not follow a consistent pattern. Five different organs of the European Commission estimated the refining footprints: for the main products, these were relatively harmonic; for minor products much less so. 
The variation was due not to a variety of physical or operational characteristics; rather, it was due to a variety of modelling methods. A clear cause of variation between the datasets was the use of different partitioning methods. This also contributed to the horizontal variation. Differing allocation keys made a difference in peripheral products, but not in the main products. Differing approaches to data sourcing and collection also contributed to the variation.

That said, absence of evidence is not evidence of absence. There might be factors other than partitioning and allocation causing significant variation that are not readily apparent. This should be explored further, e.g., via a thorough comparison of the input data, system boundaries and other sources of model uncertainties, as well as the resulting inventories for the refinery operations (with crude oil input as the functional unit) from the various sources. This paper's main point is that the resulting variation in the product carbon footprints was significant, that this is significant in policy and commercial decisions, and therefore, this variation should be further understood and addressed.

As stressed repeatedly in this work, the variety of footprints is important not only to researchers but to policymakers and actors up and down the petroleum supply chain because petroleum footprints are significant in general and they are increasingly used to inform regulations. As such, what should be done? Probably the most important action is to improve transparency. All of the models examined are somewhat opaque: it is difficult or impossible for even experienced analysts to understand their inner workings. Black box models in refining are inherently less accurate and more opaque, and therefore, are less preferable to unit-process, engineering-based models. In industries where unit-process data are unavailable, black boxes would still be acceptable. As for the use of attributional versus marginal/consequential perspectives for decision-making, this is an ongoing debate that is larger than, and peripheral to, this study. What can be said is the "horses for courses" argument, i.e., that each method probably suits certain broader objectives of policy or commerce, where more transparency will improve the understanding of the strengths and limitations of both approaches for a given context.

Author Contributions: Both authors made considerable contributions to the design, analysis and discussion of the study presented in the present paper. Both authors have read and agreed to the published version of the manuscript.

Funding: This research received no external funding.

Conflicts of Interest: The authors declare no conflict of interest.

\section{References}

1. BP Plc. Statistical Review of World Energy 2020, 69th ed.; BP Plc: London, UK, 2020. Available online: https: //www.bp.com/en/global/corporate/energy-economics/statistical-review-of-world-energy.html (accessed on 7 November 2020).

2. Masnadi, M.S.; El-Houjeiri, H.M.; Schunack, D.; Li, Y.; Englander, J.G.; Badahdah, A.; Monfort, J.-C.; Anderson, J.E.; Wallington, T.J.; Bergerson, J.A.; et al. Global carbon intensity of crude oil production. Science 2018, 361, 851-853. [CrossRef] [PubMed]

3. Jing, L.; El-Houjeiri, H.M.; Monfort, J.-C.; Brandt, A.R.; Masnadi, M.S.; Gordon, D.; Bergerson, J.A. Carbon intensity of global crude oil refining and mitigation potential. Nat. Clim. Chang. 2020, 10, 526-532. [CrossRef]

4. D.G. Energy; Exergia; E3M Lab; COWI. Study on Actual GHG Data for Diesel, Petrol, Kerosene and Natural Gas. Available online: https:/ec.europa.eu/energy/sites/ener/files/documents/Study\%20on\%20Actual\% 20GHG\%20Data\%20Oil\%20Gas\%20Executive\%20Summary.pdf (accessed on 7 November 2020).

5. Malins, C.; Galarza, S.; Baral, A.; Brandt, A.; El-Houjeiri, H.; Howorth, G.; Kodjak, D. Upstream Emissions of Fossil Fuel Feedstocks for Transport Fuels Consumed in the European Union. Available online: https://circabc.europa.eu/sd/a/6215286e-eb5f-4870-b92f-26acff386156/ICCT_Upstream-emissionsof-EU-crude_May2014.pdf. (accessed on 7 November 2020).

6. Malins, C.; Galarza, S.; Baral, A.; Brandt, A.; Howorth, G. The Development of a Greenhouse Gas Emissions Calculation Methodology for Article 7a of the Fuel Quality Directive. Available online: https:/ec.europa.eu/ clima/sites/clima/files/transport/fuel/docs/icct_crude_ghg_calculation_methodology_en.pdf (accessed on 7 November 2020). 
7. European Commission. Fuel Quality Directive 2018 Revision. Available online: https://ec.europa.eu/clima/ policies/transport/fuel_en (accessed on 7 November 2020).

8. California Air Resources Board. LCFS Crude Oil Life Cycle Assessment. Available online: https://ww2.arb. ca.gov/resources/documents/lcfs-crude-oil-life-cycle-assessment (accessed on 7 November 2020).

9. Moretti, C.; Moro, A.; Edwards, R.; Rocco, M.V.; Colombo, E. Analysis of standard and innovative methods for allocating upstream and refinery GHG emissions to oil products. Appl. Energy 2017, 206, 372-381. [CrossRef]

10. CONCAWE; Catalá, F.C.; Fuente, R.F.; de la Gardzinski, W.; Kawula, J.; Hille, A.; Fredriksson, M. Oil Refining in the EU in 2020, with Perspectives to 2030. 2013. Available online: https://www.researchgate.net/publication/ 297770727_Oil_refining_in_the_EU_in_2020_with_perspectives_to_2030 (accessed on 7 November 2020).

11. Abella, J.P.; Bergerson, J.A. Model to Investigate Energy and Greenhouse Gas Implications of Refining Petroleum. Environ. Sci. Technol. 2012, 46, 13037-13047. [CrossRef] [PubMed]

12. Sphera; IFP; EUCAR. Attributional vs Consequential LCA Methodology Overview, Review and Recommendations with focus on Well-to-Tank and Well-to-Wheel Assessments. Available online: https://www.eucar.be/lca-in-wtt-and-wtw-review-and-recommendations/ (accessed on 7 November 2020).

13. CONCAWE. Estimating the Marginal CO2 Intensities of EU Refinery Products. Available online: https://www.concawe.eu/publication/estimating-the-marginal-co2-intensities-of-eu-refinery-productsreport-117/ (accessed on 7 November 2020).

14. CONCAWE. Refinery 2050: Conceptual Assessment. Available online: https://www.concawe.eu/ publication/refinery-2050-conceptual-assessment-exploring-opportunities-and-challenges-for-the-eurefining-industry-to-transition-towards-a-low-co2-intensive-economy/ (accessed on 7 November 2020).

15. Unnasch, S.; Riffel, B.; Sanchez, S.; Waterland, L. CRC Report No. E-88 Review of Transportation Fuel February 2011. (February), 191. Available online: http://crcsite.wpengine.com/wp-content/uploads/2019/05/ E-88-Report-v8-Final-2011.03.02.pdf (accessed on 7 November 2020).

16. ESU-Services; Jungbluth, N.; Meili, C.; Wenzel, P. Life Cycle Inventories of Oil Refinery Processing and Products. Available online: http://esu-services.ch/data/public-lci-reports/ (accessed on 7 November 2020).

17. Schrijvers, D.; Loubet, P.; Sonnemann, G. Archetypes of Goal and Scope Definitions for Consistent Allocation in LCA. Sustainability 2020, 12, 5587. [CrossRef]

18. Ecofys. Greenhouse Gas Impact of Marginal Fossil Fuel Use. Available online: http://www.ecofys.com/files/ files/ecofys-2014-ghg-impact-of-marginal-fossil-fuels.pdf (accessed on 14 May 2016).

19. The Ecoinvent Association. Petroleum Refinery Operations, RER wiithout CH, Ecoinvent V 3.6. The Ecoinvent Life Cycle Inventory Database. Available online: www.ecoinvent.com (accessed on 9 November 2020).

20. Eurobitume. Life Cycle Inventory: Bitumen. Available online: https://www.eurobitume.eu/fileadmin/pdfdownloads/LCI\%20Report-Website-2ndEdition-20120726.pdf (accessed on 7 November 2020).

21. Eurobitume. Eurobitume Life-Cycle Inventory for Bitumen, Version 3.0. Available online: https: //www.eurobitume.eu/fileadmin/Feature/LCI/EB.LCI.Report.Jan2020.Pages_Interactive.pdf (accessed on 7 November 2020).

22. Directorate General Climate, European Commission; Ricardo Energy \& Environment; E4tech; IFEU. Determining the Environmental Impacts of Conventional and Alternatively Fuelled Vehicles through LCA-Interim Report. Final Report. Available online: https:/op.europa.eu/en/publication-detail/-/ publication/1f494180-bc0e-11ea-811c-01aa75ed71a1 (accessed on 7 November 2020).

23. Edwards, R.; Larive, J.-F.; Mahieu, V.; Rounveirolles, P. Well-to-Wheels Analysis of Future Automotive Fuels and Powertrains in the European Context. Available online: https://www.co2star.eu/publications/Well_to_ Tank_Report_EU.pdf (accessed on 7 November 2020).

24. Thinkstep. Environmental Footprint (EF) Secondary Data Sets Version EF 2.0. Available online: http: //lcdn.thinkstep.com/Node/ (accessed on 7 November 2020).

25. Babusiaux, D. Allocation of the $\mathrm{CO} 2$ and Pollutant Emissions of a Refinery to Petroleum Finished Products. Oil Gas Sci. Technol. Rev. IFP 2003, 58, 685-692. [CrossRef]

26. Babusiaux, D.; Pierru, A. Modelling and allocation of CO2 emissions in a multiproduct industry: The case of oil refining. Appl. Energy 2007, 84, 828-841. [CrossRef]

27. Tehrani-Nejad, M.A. Allocation of $\mathrm{CO} 2$ emissions in petroleum refineries to petroleum joint products: A linear programming model for practical application. Energy Econ. 2007, 29, 974-997. [CrossRef] 
28. Prieur, A.; Tilagone, R. A Detailed Well to Wheel Analysis of CNG Compared to Diesel Oil and Gasoline for the French and the European Markets. SAE Tech. Pap. Ser. 2007. [CrossRef]

29. PlasticsEurope; Boustead, I. Naphtha: Eco-profiles of the European Plastics Industry. Available online: https://www.plasticseurope.org/en/resources/eco-profiles (accessed on 1 June 2018).

30. Furuholt, E. Life cycle assessment of gasoline and diesel. Resour. Conserv. Recycl. 1995, 14, $251-263$. [CrossRef]

31. ISO. Environmental Management_Life Cycle Assessment_Principles and Framework; International Organization for Standardization: London, UK, 2006.

32. FuelsEurope. Statistical Report 2019. Available online: https://www.fuelseurope.eu/publication/statisticalreport-2019/ (accessed on 1 June 2018).

33. Joint Research Centre of the EU Commission; EUCAR; CONCAWE. Well-to-Wheels Analysis of Future Automotive Fuels and Powertrains in the European Context (Version 2b); Publications Office of the European Union: Luxembourg, 2011. [CrossRef]

34. European Commission. Renewable Energy Directive II (RED II). Offic. J. Eur. Union 2018, 328, 82-209.

35. National Energy Technology Laboratory; US Dept of Energy. Development of Baseline Data and Analysis of Life Cycle Greenhouse Gas Emissions of Petroleum-Based Fuels. Available online: www.netl.doe.gov (accessed on 9 November 2020).

36. Fehrenbach, H.; Liebich, A.; Abdalla, N.; Biemann, K.; Fröhlich, T.; Simon, B. Petroleum Refinery Industry and Liquid Fuels; Institut für Energie und Umweltforschung (IFEU): Heidelberg, Germany, 2017; pp. 16-17.

37. Pierru, A. Allocating the CO2 emissions of an oil refinery with Aumann-Shapley prices. Energy Econ. 2007, 29, 563-577. [CrossRef]

38. Pierru, A. Economics and the Refinery's CO2Emissions Allocation Problem. Oil Gas Sci. Technol. Rev. IFP 2007, 62, 647-652. [CrossRef]

39. ESU-Services; Meili, C.; Jungbluth, N.; Wenzel, P. Life Cycle Inventories of Long-Distance Transport of Crude Oil; ESU-Services Ltd:: Schaffhausen, Switzerland, 2018.

Publisher's Note: MDPI stays neutral with regard to jurisdictional claims in published maps and institutional affiliations.

(C) 2020 by the authors. Licensee MDPI, Basel, Switzerland. This article is an open access article distributed under the terms and conditions of the Creative Commons Attribution (CC BY) license (http://creativecommons.org/licenses/by/4.0/). 